\title{
Pensar el cuerpo de las mujeres: cuerpo, belleza y feminidad. Una necesaria mirada feminista
}

Elsa Muñiz*

Resumen: En este texto me interesa discutir la importancia de dirigir el análisis feminista hacia los cuerpos de las mujeres en las sociedades contemporáneas de América Latina, sobre todo a partir del auge de un conjunto de discursos y prácticas que llevan a cabo las mujeres cuyo objetivo es alcanzar los más altos estándares de belleza y perfección bajo ciertas normas y cualidades exigidas por la cultura de la imagen y el consumo, características de nuestros tiempos. Considero que un tema privilegiado es el de las cirugías cosméticas que en nuestros países han proliferado como prácticas cotidianas aun a costa de la salud y de los efectos colaterales que muchas de estas intervenciones propician en los cuerpos de las mujeres. Es así como en el presente ensayo muestro la manera en la que la cultura de género hegemónica se reitera constantemente a partir de las representaciones de la feminidad que giran en torno a las bellezas ya a la perfección como norma.

Palabras clave: cuerpo, mujer, feminismo, belleza, cirugía cosmética.

\section{Presentación}

Las mujeres perfectas: belleza y feminidad

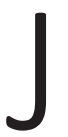

oanna y Walter viajan en su auto con su dos pequeños hijos. Pretenden alejarse del ruido de la gran ciudad y deciden asentarse en el suburbio de una pequeña localidad. Ante ellos se presenta un panorama cautivador, de una belleza incuestionable. Amplias avenidas, casas rodeadas de bellos jardines, sin bardas ni rejas. Al frente de cada casa una mujer encantadora, portadora de una rubia cabellera, con un maquillaje perfecto, un lindo vestido en color pastel, con delantal y zapatillas de tacón alto. Una de ellas riega el jardín, otra juega con los niños, alguna más recoge la correspondencia del buzón. Llegaron a Stepford, el lugar de las mujeres perfectas. Por el camino rumbo a la que sería su nueva casa no se ve a ningún marido, solamente las esposas sonrientes volteando a su paso y saludando amablemente. Para ella fue curioso, para él maravilloso. Era el mundo ideal. Walter pronto se uniría al club de maridos felices y Joanna se percataría de que algo extraño sucedía con todas aquellas mujeres hermosas y obedientes.

Esta es la narración de un pasaje del filme Las mujeres perfectas cuya trama gira en torno a la feminidad. Las mujeres de Stepford son cyborgs, les han integrado un me-

\author{
* Universidad \\ Autónoma \\ Metropolitana \\ Xochimilco. \\ Coordinadora de \\ la Maestría en \\ Estudios de la Mujer, \\ División Social de \\ Ciencias Sociales \\ y Humanidades. \\ <muniz.elsa.garcia@ \\ gmail.com>.
}


1. Según se cuenta en las crónicas de sir Gaston Camille Charles Maspero, prominente francés que dirigió el Service d'Antiquités Egyptiennes de 1881 a 1914. Fue profesor de egiptología en "École des Hautes Études" y luego de filología y arqueología egipcia en el "Collège de France", en 1874. canismo electrónico para controlar sus actos, sus emociones y sus cuerpos. La perfección es la normalidad en este lugar idílico, todas las mujeres son prácticamente iguales, se parecen físicamente y actúan de manera similar.

Basada en una novela de Ira Levin escrita en 1972, la primera versión de esta cinta data de 1975 y se tituló The Stepford wives, una segunda versión fue la de 2004, es la relatada arriba. Con variaciones en términos de ubicación sociohistórica, la trama abunda en los temas que al escritor le interesó destacar, los relativos a la sumisión y el control de las mujeres y la belleza femenina como exigencia. Resulta conveniente para este análisis recuperar la alegoría del filme para señalar lo que ya se ha discutido desde los años sesenta, la representación de la feminidad basada en un ideal de belleza y perfección interpela a las mujeres de carne y hueso de todas las capas sociales.

En el siglo XIX se afianzó esta idea de la feminidad ligada a la belleza, la fragilidad y la delicadeza del cuerpo de las mujeres. Con esa mirada decimonónica, los historiadores y demás estudiosos, recuperaron el "pasado de la humanidad" de manera eurocentrista y androcéntrica buscando en ese pasado, los valores estéticos predominantes en sus sociedades. Fue un momento en el desarrollo de la humanidad en la que la civilización occidental impuso, inexorablemente, modelos de belleza a las mujeres, de su tiempo y de otros tiempos, de su cultura y de otras culturas que permanecen hasta nuestros días. Por ejemplo, la reina egipcia Nefertiti quien fuera "una mujer decidida y enérgica, cuya belleza era alabada", ${ }^{1}$ ha sido considerada como la poseedora del "perfil más bello de la historia". Siempre estuvo obsesionada con su belleza, cuidándola continuamente con afeites y cremas que ella misa elaboraba. En el busto que se conserva de ella se advierte un auténtico "cuello de cisne", una nariz de "rara armonía" y una boca de labios carnosos perfectamente dibujados (Bravo, 1996). En la descripción de sus rasgos faciales se advierte la mirada eurocentrista de quien así ha catalogado a la reina egipcia, señalando cualidades que para los occidentales constituían sus referentes estéticos.

En las sociedades contemporáneas caracterizadas por una exigencia cada vez mayor de cuerpos perfectos, bellos y saludables, se han adoptado y producido una gama de modelos de belleza tanto para hombres como para mujeres, en los que se desconoce y se excluye cualquier tipo de diferencia. Tales patrones promueven la discriminación racial, la de los discapacitados y por supuesto de quienes no cumplen con las características de belleza que se le atribuyen a la piel blanca, al cabello rubio, a los ojos claros, la nariz "respingada", la estatura y la delgadez extrema. Es el caso de la imposición de estándares corporales a una sociedad heterogénea como la mexicana y, podríamos afirmar, de la latinoamericana donde al mismo tiempo que se difunde un reconocimiento a la diferencia, los elementos discriminatorios y excluyentes se han vuelto cotidianos. 
Alcanzar dichos estándares de belleza y transformar los cuerpos en "cuerpos perfectos" es en uno de los objetivos fundamentales de la existencia de los sujetos. Los márgenes de normalidad son tan estrechos que frente a la imagen corporal creada, aceptada y promovida desde los diversos discursos, los cuerpos anómalos aumentan. Ahora debemos luchar contra la obesidad y la gordura, mantener la piel firme, el rostro terso y sin arrugas, el cabello sin canas, las formas bien definidas, en fin, hay que corregir lo que no se encuentre acorde con el modelo. De ahí que las prácticas de la cirugía cosmética sean cada vez más comunes en todos los sectores sociales ${ }^{2}$ ocasionando efectos de diversa índole, siendo los más significativos los relacionados con la auto-percepción de los sujetos ya que las modificaciones corporales como la "corrección" de las facciones del rostro (nariz, pómulos, ojos, labios, barbilla), las alteraciones a la masa corporal (liposucción, implantes), hasta el cambio de sexo, tienen implicaciones en su definición identitaria y sus procesos de subjetivación. Se ha reconocido, por ejemplo, que las llamadas etnocirugías (Muñiz, 2010b) ocupan un primerísimo lugar para efectos de blanquear la piel, agrandar los ojos o modificar la "nariz mestiza" o la "nariz judía".

Por otro lado, sabemos que los sectores medios han sido tradicionalmente los grupos sociales con mayores posibilidades económicas y con más acceso a la información y a los medios masivos de comunicación. Asimismo muestran una clara vocación consumista encaminada a seguir los dictados de la moda, no obstante, el creciente aumento de intervenciones cosméticas ha llegado a los individuos de bajos recursos quienes recurren a lugares clandestinos donde los practicantes de dicha disciplina médica son improvisados o aprendices ocasionando, en muchas ocasiones, secuelas permanentes y en otras llevando a la muerte a los y las pacientes incautos, lo que convierte a este fenómeno en un problema de salud pública.

En este breve ensayo me interesa mostrar la importancia que tiene la mirada feminista en el análisis y crítica de las concepciones sobre la belleza que caracterizan a las sociedades contemporáneas, así como el conjunto de prácticas que materializan los cuerpos de las mujeres en términos de los patrones de perfección exigidos, en particular abundo en la cirugía cosmética en tanto dispositivo de control de las mujeres que produce sujetos de género. En este sentido, considero fundamental que desde los feminismos se discutan estas problemáticas contemporáneas, no solo porque el feminismo y el análisis de género han puesto la mirada en el desmantelamiento de la diferencia sexual como lo preestablecido, lo biológico y lo corporal, sino porque su crítica ha socavado la noción de feminidad donde la belleza se constituye en un imperativo para las mujeres.

Así, dedico un apartado de este texto a la reflexión en torno a la mirada feminista sobre el mito de la feminidad. Un segundo apartado en el que expongo la manera
2. México ocupa el segundo lugar en número de cirugías estéticas en América Latina, después de Brasil y le siguen Argentina y Colombia. Las intervenciones más frecuentes son la rinoplastia (cirugía de nariz), la colocación de implantes mamarios y la liposucción [...]. En el Hospital General de México, el 20 por ciento de las cirugías que se realizan son estéticas y el resto reconstructivas, de éstas, la intervenciones de mano ocupa 35 por ciento, la de labio y paladar hendido 15 por ciento y la de secuelas de trauma 30 por ciento ( $L a$ Jornada: 16 de Junio 2008). 
en la que las prácticas corporales de la belleza como la cirugía cosmética asumen un carácter performativo y materializador de los sujetos de género.

\section{El feminismo y el mito de la belleza}

Casi al mismo tiempo que apareció la citada cinta The Stepford wives, en el contexto del feminismo de los setenta surgió el importante trabajo editado por las mujeres del Colectivo de Boston Our bodies, ourselves, mismo que ha sido traducido a diversos idiomas y ha recorrido el mundo entero. Este libro pionero vio la luz en 1973 y recogió las discusiones que tuvieron las mujeres reunidas en un taller que llamaron Women and their bodies, en el marco de una de las primeras conferencias feministas celebrada en Boston. Muchas de estas mujeres eran activistas en contra de la Guerra de Vietnam y para algunas de ellas esta reunión significó su primer encuentro con el feminismo. Las mujeres hablaron de su sexualidad, del aborto, de sus experiencias con el embarazo, la maternidad y la infancia; y sus frustraciones con la atención a la salud por parte de médicos y especialistas en el tema. Este grupo, que más tarde se convertiría en Boston women's health book collective, comenzó a reunirse regularmente, sus miembros recogieron información sobre temas de salud y escribieron textos que discutieron en reuniones a las que acudían cada vez más mujeres. Un año después de las discusiones el grupo decidió agrupar estos trabajos y publicar lo que sería la primera versión de este entrañable libro que fue publicado por un editor marginal y vendido a un precio de 75 centavos (Davis, 2007: 1).

Los debates sobre la despenalización del aborto, la violencia hacia las mujeres y la crítica al cuerpo femenino desensualizado y destinado a la reproducción, configuraron la denuncia contra la enajenación de los cuerpos y configuraron la principal demanda del feminismo de la segunda ola: el derecho a decidir sobre el propio cuerpo. A partir de tales controversias las feminista plantearon una guerra frontal con la promoción de lo que aquellos años se categorizó como la "mujer objeto". Estas nociones hegemónicas de la feminidad provocaron que el feminismo de los años sesenta, en casi todo el mundo occidental, trajera a la discusión el cuerpo de las mujeres tocando otros temas demás de la salud. El feminismo cuestionó el "imperio de las imágenes" como se ha referido Susan Bordo (2003) a la influencia de los medios sobre la definición de la corporalidad de las mujeres y se pronunció en contra de los concursos de belleza, los afeites y de la "belleza ideal" como un requisito para ser mujeres. Baste recordar la quema de brassieres en el Cementerio de Arlington con aquella consigna que levantaron las mujeres en 1968 “¿Cubrirá el maquillaje las heridas de nuestra opresión?", cuando se apostaron fuera de la sede donde se elegía a Miss América (Ergas, 1993). Expresiones que fueron reproducidas en nuestro país pues las feministas mexicanas también salieron a la calle y se apostaron frente a recintos como el Auditorio Nacional para pronunciarse contra los certámenes de belleza. 
Como podemos ver, desde el feminismo se han analizado los modelos de belleza, tanto en su carácter cosificador del cuerpo de las mujeres, como su obligatoriedad desde una mística de la feminidad (Friedan, 1963). Asimismo, el cuerpo ha estado sometido a escrutinio en virtud de los debates que el propio feminismo planteó respecto de la relación naturaleza-cultura propios de la visión occidental que ha establecido la diferencia entre sexo y género y ha considerado al cuerpo como la matriz biológica para comprender la construcción del género y su implicación en la definición de la feminidad. Finalmente, en las discusiones se ha abundado en las maneras en las que se constituyen las diferencias a lo largo de las líneas trazadas por la clase social, la "raza", la etnia, la nacionalidad, la sexualidad, las capacidades corporales y más (De Lauretis, 1986; Butler, 1989; Bordo, 2003).

\section{La autogestión corporal ¿Un espejismo?}

Delgadez, belleza, flexibilidad, agilidad para el trabajo y para el placer, son las metas individuales de quienes toman el cuerpo en sus manos. Decidir sobre sus cuerpos es arbitrar sus propias vidas. Este es el mensaje de uno de los filmes más emblemáticos de la década de los ochenta. Flashdance (1983) muestra, parafraseando a Alejandra Kollontai (1972) a la mujer nueva y la moral sexual que se pretende reconocer hacia finales del siglo XX, poseedora de un cuerpo que ella misma controla. Se desarrolla en la ciudad industrial de Pittsburgh en USA, la protagonista es una chica que arduamente trabaja para ganarse la vida desempeñando una labor antes solamente aceptada para los hombres como es el oficio de soldador. Vive sola, es independiente, no requiere la ayuda de nadie y por las noches baila en un bar para ejercitar sus rutinas. Su deseo es ingresar en una reconocida academia de danza y se somete a ejercicios y disciplinas férreas que ella misma diseña para mantener la elasticidad de sus movimientos y la firmeza de sus músculos. Exhibe su cuerpo sin falso pudor, ejerce su sexualidad libremente. Recuperar el cuerpo es recuperar el yo, tal como lo habían reivindicado las feministas de los setenta. Esta nueva mujer es la que se hace a sí misma.

De este modo, los años ochenta inauguraron la noción del cuerpo como una confección de sí mismo convirtiéndose en uno de los objetivos personales más relevantes en las sociedades postindustriales. En un contexto de crisis e incertidumbres, el cuerpo de los sujetos representaba algo más que sus capacidades físicas, adquirió una importante significación para su propia existencia al tener la posibilidad de construirse de la manera en la que le gustaría ser. La protagonista del filme narrado aquí, muestra claramente que en las sociedades contemporáneas lo individual responsabilidad del propio actor. Disciplina corporal, para el baile de la vida; esfuerzo y trabajo para lograr el éxito y la fama.

Bajo un tipo de relaciones sociales en las que el Estado parce haber dejado el campo libre al mercado para ejercer poder y control sobre los individuos, no solo se promovía 
el ejercicio y la preparación física para lucir jóvenes, bellos y exitosos, lo exigía como una condición de felicidad. Indudablemente, la preocupación por el cuerpo y su apropiación, han significado un avance al considerar la identidad como un proyecto, a la vez que hace evidente la presencia del cuerpo como parte fundante de la subjetividad y subraya su perfil de producto social, sin embargo, como metáfora cultural, el cuerpo representa lo paradójico de las sociedades actuales, pues observamos un mayor control sobre los individuos y sus cuerpos, así como un desprecio por la carnalidad de los sujetos.

Fue a partir de los años ochenta y hasta nuestros días que la inquietud por el cuerpo se exacerba. Las mujeres suponen que sus cuerpos la única verdad de su ser, su muy personal espacio de decisión y acción. La ciencia y las actuales prácticas corporales han permitido que en las sociedades contemporáneas el cuerpo de los sujetos represente algo más que sus capacidades físicas, que adquiera una importante significación para la autogestión de la propia existencia al tener la posibilidad de construirse a la medida de sus deseos. En la concepción actual del sujeto, el cuerpo es una creación más de la empresa personal. La sociedad prepara y alienta a los individuos para procurarse un cuerpo que ostente juventud, delgadez y sensualidad; en tanto que debemos rechazar el cuerpo decadente, envejecido o discapacitado.

Las experiencias corporales de las mujeres, en relación a su apariencia, han sido exploradas desde las prácticas más cotidianas de belleza, los tratamientos para adelgazar y las modas; la reciente "epidemia" de los desórdenes alimenticios (bulimia y anorexia), así como la cirugía cosmética. Los estudios culturales, desde una perspectiva feminista, han promovido la investigación sobre la representación del cuerpo femenino en el cine y la televisión, mostrando la manera en la que los medios de comunicación "normalizan" a las mujeres presentando imágenes del cuerpo femenino como glamorosamente opulento, imposiblemente delgado e invariablemente blanco ( Davis, 1997).

En nuestras sociedades actuales, la búsqueda de la belleza y la perfección ha desplegado una de las industrias más exitosas. Los cosméticos, los tratamientos, las clínicas y salas de belleza, llamadas "estéticas", así como las modificaciones faciales y corporales, son constitutivas del dispositivo de la corporalidad; son un conjunto de prácticas complejas que, por un lado, podemos considerar como alegorías de la reapropiación de los cuerpos y formas de expresión de la consabida auto-creación de la identidad, y por otro como mecanismos disciplinarios en el proceso de controlar los cuerpos. Es innegable la popularidad de dichas prácticas y el aumento de consumidores de este tipo de servicios, no obstante, la proliferación de intervenciones quirúrgicas encaminadas a modificar los cuerpos de mujeres y hombres en busca de la perfección y la belleza, generan algunos interrogantes: ¿Cómo definir el impacto de las modificaciones corporales en la identidad y subjetividad de las personas? ¿Hasta dónde, tales modificacio- 
nes, obedecen a las decisiones autónomas de los sujetos? ¿En qué medida podemos considerarlo un acto de normalización más que de embellecimiento?

Indudablemente, en términos de la modernidad, las modificaciones corporales implican un "desafío a la "naturaleza" y un triunfo de la ciencia y la cultura. Sin embargo, también revelan la paradoja de apelar a las normalidades establecidas desde la cultura, justificadas por un discurso de lo natural y lo biológico, es decir, las alteraciones a la corporalidad son un reto a los procesos de naturalización del género, podemos confirmar lo anterior al observar que las operaciones realizadas en los cuerpos de las mujeres, regularmente tienden a enfatizar, en las primeras, los rasgos de la feminidad, es decir, aumentar el tamaño de senos, de los glúteos y se afinan los rasgos faciales; en el caso de los varones, se aumentan los pectorales y bíceps, se aplican injertos en la cabellera o se aplican prótesis en el pene. Contradicción que se hace evidente en el caso de las operaciones de reasignación sexual que responden a la argumentación quienes se practican este tipo de intervenciones, de haber nacido "en el cuerpo equivocado".

Las prácticas de belleza como la cirugía cosmética, en su carácter normalizador, también han trazado la interconexión entre racismo y cuerpo, mostrando cómo los modelos de belleza han sido centrales para los procesos de exclusión y discriminación. A principios del siglo XIX, los científicos justificaron la expansión colonial con argumentos biológicos acerca de la superioridad de los tipos raciales europeos. Las diferencias raciales han desentrañado la definición de la "otredad", el poder y las jerarquías también entre las mujeres. Por ejemplo, la piel blanca y luminosa, base del ideal femenino de la belleza occidental es una aspiración de las mujeres de piel obscura, nariz ancha y cabello rizado (Davis, 1997). La "representación" de la mujer que incluye a todas las mujeres blancas occidentales requiere de una "otra" u "otras": las mujeres de color y las mujeres de los países no occidentales, indígenas, mestizas, mulatas, asiáticas. Entender la diferencia a partir del sexo biológico y/o la "raza" legitima las desigualdades sociales que se establecen como inmutables porque se sustentan en la "naturaleza" y van de la mano con el esencialismo y la homogeneización (Muñiz, 2007).

\section{Belleza y performatividad}

Vivimos una época en la que la belleza del cuerpo femenino es tan importante como la del rostro y ninguna mujer puede, hoy en día, permitirse el lujo de despreocuparse de su línea. Existen, sin embargo, otras razones que justifican esta preocupación que en un principio puede parecer pueril o simplemente ser tachada de narcisista. Entre ellas y por poner un ejemplo se encuentra alcanzar el éxito en la vida...La mujer ahora está obligada a proteger y mante- 
ner su línea por múltiples razones: por ella misma, por dignidad, por su marido que presionado por el símbolo femenino impuesto por la media le obliga a establecer inevitables comparaciones y por sus hijos, que al crecer, también se encontrarán "condicionados" por la presión del entorno. Pero es sobre todo el compromiso que la mujer ha adquirido con la vida activa lo que le obliga a vigilar su línea (Rouet, 1995: 19-20).

Esta cita corresponde a un texto escrito en 1990 por Marcel Rouet y traducido al español cinco años después. Es uno de tantos libros de autoayuda que circulan y son consumidos en almacenes y tiendas de autoservicio y que de muchas maneras se convierten en educadores de mujeres y jóvenes de clase media. En este libro que al menos lleva dos ediciones, la autora afirma que en nuestros días "la mujer atractiva es dueña de su vida". Desde esta perspectiva, la belleza es una herramienta para las mujeres, una moneda de cambio.

Partiendo de estas afirmaciones podemos plantear algunas preguntas que interpelan a las diversas posturas feministas ¿se ha reinstaurado el cuerpo de las mujeres como cuerpo para otros? O más bien ¿nunca hemos sido las mujeres dueñas de nuestro cuerpo? Como señalamos antes ¿ha sido un espejismo pensar en que decidimos sobre nuestros cuerpos?

La belleza como un conjunto de conceptos, representaciones, discursos y prácticas cuya importancia radica en su capacidad performativa en la materialización de los cuerpos sexuados y en la definición de los géneros. Sabemos, que hasta nuestros días, la belleza se considera una característica de la feminidad, tanto como se concebía en el siglo XIX, y se ha pensado como una obligación para las mujeres ser bellas. La belleza se constituye entonces, en parte de la normalidad femenina que se impone a los cuerpos de las mujeres a través de prácticas identificatorias gobernadas por esquemas reguladores.

Siguiendo a Georges Vigarello (2005), podemos decir que la belleza es histórica, plantea diferencias en sus códigos tanto como en las maneras de enunciarla y de mirarla. La belleza es social y sus criterios estéticos directamente experimentados en la atracción y el gusto, se enuncia en los gestos y en las palabras cotidianas (Vigarello, 2005: 10). Implica también la belleza expresada por los actores, observada por ellos; sus normas, sus perfiles y también al de los medios de embellecimiento o conservación de la belleza, los que dan sentido al cuidado, a los ungüentos, a los afeites, a los secretos. Alude a lo que gusta o disgusta del cuerpo en cada cultura y en determinado tiempo, a las apariencias que se valorizan, a los contornos que se enfatizan o se desprecian. A su alrededor se constituyen imaginarios que emergen a la superficie de los cuerpos; comprende el aspecto y los modales, involucra el "sobrecogimiento de 
los sentidos, la inopinada sensación de no poder describir la perfección" (Vigarello, 2005: 11).

En un análisis de la belleza no puede dejar de considerarse los modelos de género y las identidades. Los esquemas de dominación ejercida sobre las mujeres, señala Vigarello (2005: 11), tienen su correspondencia con el universo estético, por ejemplo, la exigencia tradicional de una belleza siempre "púdica", virginal, vigilada, se impuso durante mucho tiempo, antes de que se consolidaran las "liberalizaciones" decisivas con repercusiones en las formas y en los perfiles, con movimientos mejor aceptados, con sonrisas más sueltas y con cuerpos más descubiertos.

Mucho se ha reflexionado acerca de la preeminencia de lo individual sobre lo colectivo en las sociedades contemporáneas, en particular, en lo referente a la importancia del cuerpo como parte del proyecto personal (Le Breton, 1990; Lipovetzki, 2004; Vigarello, 2005). No obstante, la tensión entre la persecución de un ideal identitário muy personal y las tendencias de los patrones de belleza imperantes en estas sociedades de la modernidad tardía, se hace evidente con el auge de la cirugía cosmética y nuevas preguntas se plantean a las estudiosas feministas ¿De qué manera estos modelos de belleza participan de la constitución de los sujetos? ¿Cómo se establece el vínculo entre las imágenes idealizadas y las prácticas de los sujetos? En este sentido, retomando a Judith Butler (2002), considero necesario poner de manifiesto la importancia de la performatividad de las prácticas y los discursos que hacen realidad lo que nombran mediante lo que la autora llama "la apelación a la cita", 3 papel que en este caso cumplen los patrones estéticos dominantes. Los procesos de identificación no se dan como un actividad imitativa mediante la cual un ser consciente se moldea a imagen y semejanza de otro, por el contario, "la identificación es la pasión por la semejanza, mediante la cual emerge primariamente el yo" (Butler, 2002: 35).

La belleza considerada como un atributo de la feminidad participa de los esquemas reguladores que hacen inteligibles los cuerpos de las mujeres únicamente si se ajustan a los requerimientos de ciertos modelos de belleza aceptados y promovidos. Entonces, las prácticas y los discursos de la belleza forman parte del proceso de materialización de los sujetos femeninos, entre ellos la cirugía cosmética, al participar de dicha materialización de los cuerpos sexuados, gobernada por normas reguladoras que determinan que un cuerpo sea viable. Contribuye también, a la creación y a la recreación de las representaciones de la feminidad produciendo las diferencias de género.

Butler (2002) señala la imposibilidad de teorizar sobre la performatividad del género al margen de la práctica forzada y reiterativa de los regímenes sexuales reguladores que parten de un cuerpo de mujer y un cuerpo de hombre; en estos regímenes de
3. Retomo esta idea de "apelación a la cita" planteada por Judith Butler, quien la explica de la siguiente manera:

"Lo que Lacan Ilama la 'asunción' o el 'acceso' a la ley simbólica puede interpretarse como una especie de 'cita' de la ley y así ofrece la oportunidad de vincular la cuestión de la materialización del 'sexo' con la concepción de la performatividad como una apelación a la cita...Si el 'sexo' se asume del mismo modo en que se asume una ley, ...luego, 'la ley del sexo' se fortalece e idealiza repetidamente como la ley solo en la medida en que se la reitere como una ley, que se produzca como tal, como el ideal anterior e inaproximable, mediante las citas mismas que esa ley ordena. Si se reinterpreta la significación que da Lacan a la 'asunción' como cita, ya no se le da a la ley una forma fija, previa a su cita, sino que se la produce mediante la cita, como aquello que procede y excede las aproximaciones mortales que realiza el sujeto" (Butler, 2002: 36-37). 
discurso-poder no concurre la posibilidad de armonizar con el voluntarismo o el individualismo ni la existencia de un sujeto que elige.

En la cultura de género vigente, las prácticas corporales como la cirugía cosmética tienen el objeto de modelar el sexo a partir de la materialización de las regulaciones impuesta por la hegemonía heterosexual, que a su vez, requiere de procesos identificatorios promotores de la asunción de tales normas y, finalmente, considerar la materialización de la norma en los cuerpos que gobierna como la producción de cuerpos que importan, del mismo modo la de aquellos cuerpos que no llegan a materializar dicha norma, serán considerados en el "exterior", es decir, la abyección (Butler, 2002: 38-39).

La perfección más allá de la norma

\begin{abstract}
¿Cómo puedo describir mis emociones ante esta catástrofe? ¿Cómo puedo delinear al monstruo que había formado, con tantos pesares y desvelos? Sus miembros eran proporcionados y yo había elegido sus facciones para que fueran hermosas; ihermosas! iGran Dios! Su piel amarilla apenas si cubría sus músculos y arterias; sus cabellos eran de un negro lustroso; sus dientes eran blancos como perlas; pero esto formaba un contraste mucho más horrible con su mirada acuosa que parecía casi del mismo color que las órbitas en las que estaban insertados sus ojos, con su tez marchita y sus labios negros y rígidos (Shelley, 2003: 79).
\end{abstract}

Estas son las reflexiones de un atormentado Dr. Frankenstein al darse cuenta de que su objetivo de dar vida a un ser perfecto había culminado en la más espantosa realidad de un ser monstruoso. Cabría preguntarnos ¿Cómo sería para el Dr. Frankenstein un ser perfecto? ¿Qué rasgos debería tener este ser para considerar que se habría alcanzado la perfección? ¿Cuáles eran sus parámetros? ¿Cuáles sus modelos? Como se ha afirmado anteriormente, la perfección es una entelequia, una fantasía que se encuentra en la mente de cada persona y que se alimenta de representaciones y de imágenes idealizadas que son históricas, que cambian con los tiempos y los lugares. En la actualidad esta perfección irreal aumenta constantemente sus exigencias, cualquier variación o diferencia del modelo es considerada un defecto que se debe corregir.

Veamos la publicidad de las clínicas de belleza que anuncian los más efectivos y seguros métodos de cirugía cosmética, la promesa es la "corrección" de aquellos rasgos faciales o de alguna parte del cuerpo con los que no nos sentimos a gusto. La pregunta que surge es inevitable ¿Porqué estamos descontentos con la nariz, con los labios, con los senos, la cadera...? ¿Con quién nos estamos comparando para saber que queremos de esta o de aquella forma el mentón o los pómulos? Las imágenes de actrices y 
actores famosos, de modelos paradigmáticas o de las reinas de belleza, aparecen en los anuncios espectaculares, circulan por la web, se muestran en las portadas de revistas; revelan los más recientes cambios en sus cuerpos y en sus rostros, exhiben una perfección quimérica en una piel tersa y en un cabello brillante, producto no solo de las cirugías cosméticas a las que se han sometido, sino de las modificaciones virtuales realizadas a través del Photoshop lo cual, como señala Susan Bordo (2003) en su notable texto Unbearable Weigth se convierten en una manera de interpretar el propio cuerpo, en una pedagogía perceptual.

Esas imágenes están enseñándonos cómo ver, son creaciones, cyborgs visuales que nos educan en lo que debemos esperar de la sangre y de la carne. Y se pregunta ¿somos lo suficientemente sofisticados para darnos cuenta de que esas imágenes no son reales? Pero, ¿acaso importa? No hay advertencias de que las imágenes son producidas por computadoras, no informan que no luciremos de la forma en la que muestran a las modelos pero ¿quién se preocupa por la realidad cuando la belleza, el amor, la aceptación, llaman? (Bordo, 2003: xviii). Esta perfección virtual es el milagro que se espera conseguir a través de diversas estrategias y prácticas corporales de belleza, desde el ejercicio, las dietas, las prendas para resaltar alguna parte de la figura, para estilizar la silueta, el maquillaje, el teñido del cabello y fundamentalmente, la cirugía cosmética como el remedio definitivo para solucionar los "defectos" de nacimiento.

Ahora no se busca ser normal sino perfecto de una manera homogénea, de tal manera que esa perfección virtual se ha vuelto la normalidad, entendida ésta como lo cotidiano, lo uniforme y por supuesto lo normativo. Por ejemplo, en el mercado encontramos prótesis de nariz, de mentón y de pómulos con formas y tamaños estandarizados. Los contornos faciales atienden a un patrón de cara ovalada del que se retiran las mejillas regordetas. Los labios voluminosos por los implantes, los injertos y las inyecciones de colágeno o ácido hialuronico y agrandados por efecto del lifting, persiguen una apariencia voluptuosa y sexy. Los ojos de color usando lentillas de contacto, agrandados y sin ojeras ni arrugas mediante una operación llamada blefaroplastia que también se realiza a mujeres y hombres de rasgos asiáticos.

Es también el caso de las prótesis de mama o de los implantes de glúteos, que se ofrecen en medidas estandarizadas. En esta búsqueda de la perfección estandarizada se pierde la diferencia. La noción de autonomía de la identidad está en riesgo. David Le Breton (2010) ha subrayado que la cultura y lo social modelan la forma y los movimientos del rostro, y la forma en la que se ofrece al mundo, es un compromiso entre las orientaciones colectivas y la manera personal en que cada actor se acomoda en ellas (Le Breton, 2010:16). No obstante en la era de la cirugía cosmética el sujeto o actor, como él lo llama, pierde su unicidad, las transformaciones que se llevan a cabo 
en los rostros en un frenesí por alcanzar la belleza aceptada hace las funciones de una máscara. En esta búsqueda la máscara o las transformaciones,

\begin{abstract}
Suele tomar las riendas, apoderarse del hombre, quien creía dominar, orientar su acción. Querer escurrirse a hurtadillas de los propios rasgos no es una intención libre de riesgos. Cambiar de rostro implica cambiar de existencia, librarse o tomar una distancia provisoria, no sin peligros, del sentimiento de identidad que hasta ese momento regía la propia relación con el mundo (Le Breton, 2010: 17)
\end{abstract}

Desde inicios de la modernidad, las mujeres fueron colocadas en el polo de lo corporal "son bellas" por "naturaleza", como señalaba Arthur Schopenhauer, "la "naturaleza" engalana a las jóvenes con una belleza, una gracia, una perfección extraordinarias" (Schopenhauer, 1991). Las mujeres deben proporcionar la belleza a las nuevas generaciones, en tanto, a los hombres les corresponde transmitir la inteligencia, la serenidad y la formalidad. En el ideal de belleza occidental para las mujeres es suficiente ser "bonitas" lo cual les autoriza para ser tontas, insustanciales y frívolas. Al mismo tiempo, la belleza femenina en occidente es la representación de virtudes morales o espirituales, en este sentido, la belleza asociada a la bondad es una condición de la feminidad y por tanto se convierte en una obligación para las mujeres.

Desde estas exigencias para las mujeres es central cultivar la apariencia y si bien los estándares de belleza han cambiado a lo largo del tiempo y en cada sociedad, la modernidad ha impuesto modelos de belleza que se presentan como imposibles de alcanzar para la mayoría de las mujeres ante las diferencias fenotípicas, de clase o de edad, aunque si se constituyen en una aspiración constante que llega a convertirse en obsesión. Las nociones sobre la belleza pertenecen al ámbito de las mentalidades, cuyos procesos de construcción, consolidación y permanencia son de muy larga duración.

Hasta el día de hoy mantenemos una concepción cartesiana de nuestros cuerpos, tenemos uno, nos pertenece y podemos transformarlo o repararlo de ahí que, no obstante los ideales estéticos que caracterizan épocas y lugares distintos, en el mundo occidental se han mantenido ciertas pautas que Schopenhauer a mediados del siglo XIX resumió de manera que podríamos calificar de jocosa, si no fuera por la adustez y el pesimismo que lo caracterizaba. De sus argumentos quiero recuperar algunos aspectos que se encuentran en el centro de tales ideales y siguen vigentes en el modelo de feminidad hegemónico contemporáneo.

Empezaremos por el factor de la edad cuando sentencia: “... la juventud sin belleza tiene siempre atractivo, pero ya no lo tiene tanto la hermosura sin juventud" (Shopenhauer, 1991:264). Los procedimientos para ocultar los signos de envejecimiento son 
variados, desde las inyecciones de la bacteria botulínica, conocida como "botox", en distintas partes del rostro, cuyo efecto paralizante, no solo desdibuja las arrugas, sino que también acaba con la expresión del rostro. Los "tirantes chinos" que literalmente "jalan" la piel produciendo efectos alisantes; o el lifting, popularmente llamado estiramiento facial, que consiste en hacer cortes en el contorno facial, estirar la piel, suturar y cortar la piel sobrante.

La importancia atribuida al esqueleto o la estructura ósea sugiere la conformación "defectuosa" o la correcta "hechura" pues, según el filósofo, es el fundamento de la especie y enfatiza que "ni aun el rostro más hermoso podría indemnizarnos de una espalda encorvada" (p. 266). Los "defectos" de la estructura es lo que más disgusta, "un talle rechoncho y enano, piernas demasiado cortas, andar cojeando... por el contrario, un cuerpo notablemente hermoso, compensa muchos defectos..." (p.266). Lo que en el siglo XIX se concebía como defectos del esqueleto ahora lo son del contorno corporal. Para alargar el talle, también existen procedimientos que consisten en cortar las costillas falsas, practicar liposucción en las partes del cuerpo que muestren grasa acumulada, y hasta retirar las capas de tejido adiposo mediante una operación que culmina con una sutura y el corte de la piel sobrante o "colgajo".

La belleza de la cara empieza por tener una nariz "bien hecha, al paso que una nariz corta y arremangada, lo desluce todo. Una nariz hacia arriba o hacia abajo ha decidido la suerte de infinidad de mujeres..." (p.267). La boca, formada por unos huesos maxilares pequeños, es una característica fundamental del rostro humano, "en oposición al hocico de los demás animales" (p. 267). La barbilla, "escurrida o amputada...es particularmente repulsiva". Como sabemos, la cirugía cosmética corrige las facciones del rostro, la más común es la rinoplastia, operación de nariz; la de pómulos, labios, ojos, papada, barbilla. Las transformaciones faciales son las que con mayor claridad muestran la adopción de los patrones estéticos hegemónicos traduciéndose en lo que se ha dado en llamar "etnocirugía".

Para el especialista en cirugía cosmética, Dr. Feliciano Blanco Dávila (2005), ${ }^{4}$ la belleza ideal y de normalidad se basan en la observación del equilibrio, de la armonía del cuerpo y del rostro; de esta forma es posible distinguir lo estético de lo que no lo es. Reconoce, sin embargo, que sigue siendo una impresión de la mente motivada por su propia percepción, la de la población, la de la cultura, la de la época que se vive, al mismo tiempo se pregunta "¿Pero existen medidas que determinen el grado de belleza de nuestros rostros y nuestros cuerpos?" (p.118).

El Dr. Blanco Dávila argumenta a favor de buscar la belleza en la armonía y el equilibrio en tanto propone recuperar el sentido estético y artístico de la cirugía cosmética. Desde sus planteamientos y a partir de algunos de los testimonios, podemos constatar 
5. Las mujeres verdaderas tienen curvas (2002) es una cinta dirigida por Patricia Cardoso basada en un guión para teatro de Josefina López. Ganó dos premios en el Festival de Sundance y el Premio a la Juventud en el Festival de San Sebastián que muchos de los practicantes de esta disciplina no piensan siempre en términos de armonía y proporción cuando intervienen a los pacientes, en muchos casos se privilegia el beneficio económico.

"Qué bonita" le dice Jimmy a Ana al verla desnuda ante el espejo. Ella quiere que antes de hacer el amor, él la vea como es: gordita, con celulitis, con llantitas. Sabe que está pasada de peso, su madre se encarga de decírselo continuamente. A ella y a su hermana las hostiga con las dietas, "no eres fea y si adelgazaras, serías linda". Ana está habituada solamente a las críticas de su madre, por eso no "acepta cumplidos", ni cree en ellos, sus expresiones lo demuestran.

Es claro que para las mujeres como la madre de Ana el cuerpo no debe mostrarse, debe esconderse y más si no cumple con los ideales estéticos. En una de las escenas más relevantes de la cinta Las mujeres verdaderas tienen curvas, ${ }^{5}$ el momento en el que Ana se quita la playera por que tiene calor, la madre se ofusca y le reclama que exhiba sus gorduras: “¿no te da vergüenza?” Las mujeres se reconocen en sus cuerpos. "Todas tenemos lo mismo" dice Ana, aunque unas más celulitis que otras, unas más senos que otras. Algunas, más vientre que otras y eso hace la variedad. "Somos mujeres reales" ¿Y tu mamá...? Le pregunta levantándole su blusa. Ana se da cuenta que su madre tiene una cicatriz de cuando ella nació, inunca la había visto! Era incapaz de mostrar su cuerpo, sus hijas no la conocían.

Mucho se ha discutido sobre el derecho a decidir sobre nuestro cuerpo, Ana con sus actitudes nos permite pensar en ello. Ana se apropia de su cuerpo y en la medida en que lo hace, decide sobre él. Ella es así: “¿Por qué siempre le dicen que adelgace?” y así muestra su cuerpo y se quiere como es no le interesa adelgazar para atrapar a un hombre. ¿Cómo decidimos sobre nuestro cuerpo, cuando decimos lo que decidimos?

Retomemos el ejemplo de Stepford, un lugar imaginario en los suburbios norteamericanos, es el escenario de la felicidad, el bienestar y la tranquilidad. Aquí "todas las mujeres son bellas, rubias, perfectas, sensuales y descerebradas", comenta una de las protagonistas del ya comentado filme Las mujeres perfectas. Pero ¿cómo hacen perfectas a las mujeres en Stepford? Uno de los artífices de la obra explica el procedimiento en una de las escenas más significativas de la cinta:

Nosotros las ayudamos, las perfeccionamos. Tomamos a una triste mujer insatisfecha. Luego en una experiencia muy privada entre esposo y esposa, él la coloca suavemente en nuestro sistema de perfeccionamiento femenino, totalmente automático y su transformación comienza. Primero localizamos su cerebro, insertamos algunos chips, luego las programamos. Además agregamos ingre- 
dientes secretos especiales: azúcar, especias, todo agradable. La mejoramos para que reúnan las especificaciones de la esposa de Stepford.

En Stepford, las mujeres son cyborgs, la tecnología permitió que sus cerebros fueran intervenidos y reestructurados para que adquirieran las características de una esposa perfecta. Sus cuerpos modificados para ser físicamente las más atractivas. Impecablemente vestidas al estilo y moda de los años cincuenta, llevan sombrero, guantes y zapatillas. Pero estas ficciones se convierten en realidad cotidiana en nuestros días, el porcentaje de mujeres "reales" que se han practicado alguna cirugía cosmética en busca de la anhelada ficción, es casi desconocido, no obstante han aparecido algunos datos poco confiables que refieren que más del $90 \%$ de quienes recurren a este tipo de prácticas son mujeres.

\section{A manera de colofón: cuerpo, género y poder}

La belleza no puede comprenderse sin tomar en cuenta el género y el poder (Bordo, 1987). Centrar el análisis feminista en las practicas de belleza, como las dietas, el ejercicio y, en particular la cirugía cosmética incluidas las imágenes de revistas, cine, televisión, espectaculares..., nos permitirá explorar las maneras en las que se establece la relación entre género, poder y corporalidad en la cultura occidental y volver a colocar en el centro de la reflexión la relación "naturaleza"-cultura tan entrañable para el pensamiento moderno y tan fundamental para la conformación de la feminidad.

Simultáneamente, podremos establecer una discusión con el constructivismo desde el cual se pretende observar el cuerpo como una superficie de inscripción o concebirlo como anterior a los discursos y por el contrario retomar los planteamientos de Butler (2002) cuando rechaza la idea del cuerpo como lo biológico al que se impone la cultura y asume que el cuerpo es el resultado de los efectos del poder productivo.

El cuerpo femenino, en este sentido, expresa precisamente estos efectos de las prácticas y los discursos sobre la feminidad como el que apuntala la propaganda y toda aquella parafernalia comercial que rodea la cirugía cosmética. Las variadas formas en las que las mujeres deben adornar o alterar sus cuerpos trabajan para borrar las diferencias entre ellas produciendo una homogenización como efecto contradictorio a la singularidad pretendida. La supresión de los significados específicos roba a las prácticas de belleza su significado político y las hace ideales para la normalización de la feminidad en todas sus formas.

Las prácticas dirigidas al mantenimiento y mejora del cuerpo se perciben como el medio para realizar el proyecto personal, así como la manera de derrotar la muerte y 
la decadencia individual. Las prácticas de belleza, principalmente la cirugía cosmética, han afianzado la idea de la instrumentalidad del cuerpo; la noción del cuerpo máquina modificable y reparable se alimenta con la convicción de que dichas prácticas prueban la toma del cuerpo en propia mano, por parte de las mujeres. Desde este planteamiento, podemos comprender que una de las principales discusiones generadas a partir de la popularización de la cirugía cosmética, sea la que coloca en el centro la agencia de los sujetos, heredera de la demanda feminista del derecho de las mujeres a "decidir sobre el propio cuerpo".

La idea de que el cuerpo puede ser controlado a través del poder, es decir, el poder de la mente sobre materia refuerza las relaciones de poder entre los sexos. Las mujeres creen que por controlar o contener sus cuerpos pueden escapar del círculo pernicioso que surge de la sensación de nunca ser tan buenas como se requiere o ser lo suficientemente bellas. Así, las mujeres paradójicamente se sienten empoderadas o liberadas a través de las normas y prácticas de belleza las cuales, en cambio, las constriñen y esclavizan.

Bordo (2003) señala la importancia de considerar la historicidad de las prácticas de belleza para vincular la individualidad a un contexto más amplio de poder y jerarquías de género, pero analizando el complejo y contradictorio trabajo de los discursos acerca del cuerpo, el control y la feminidad. Bordo muestra porqué las mujeres son especialmente susceptibles a los señuelos del sistema de belleza. Las prácticas de belleza no son simplemente un artefacto de consumo capitalista, de la feminización de la cultura o de las contradicciones de la modernidad, es central a la reproducción de relaciones de dominación y subordinación, al perpetuar las limitaciones y los efectos disciplinarios de la feminidad.

El análisis de las prácticas y los discursos culturales sobre la belleza, proveen de invaluables significados para comprender no solo los procesos a través de los cuales se lleva a cabo la materialización de los cuerpos, también nos permite conocer las razones por las cuales las mujeres persisten en mejorara o alterar sus cuerpos a pesar de los peligros y los inconvenientes de la mayoría de las prácticas de belleza.

Abstract: In this text I'm interested in discussing the importance of leading feminist analysis to the bodies of women in contemporary societies in Latin America, especially since the rise of a set of discourses and practices carried out by women whose goal is to achieve the highest standards of beauty and perfection under the standards and qualities required by the image culture and consumption characteristics of our times. I believe that a privileged issue is cosmetic surgeries that have proliferated in our countries as everyday practices at the cost of health and the side effects that many of these surgeries contributed to women's bodies. Thus, in the present trial show the way in which hegemonic gender culture constantly reiterates from representations of femininity that revolve around the beauty and perfection as standard.

Keywords: body, woman, feminism, beauty, cosmetic surgery. 


\section{Referencias}

Blanco DávILA, Feliciano. Las proporciones divinas. Cirugía Plástica, v. 15, n. 2, 2005, p. 118-124.

BORDO, Susan. The fligth to objectivity: essay on cartesianism and culture. Albany: Suny Press, 1987.

. Unbearable weight. Feminism, Western culture and the body. Berkeley: University of California Press, 1993.

BUTLER, Judith. Gender trouble. Feminism and the subversion of identity. New York: Routledge, 1989.

- Cuerpos que importan. Sobre los límites materiales y discursivos del "sexo". México: Paidós, 2002.

BRAVo, Ángela. Femenino singular. La belleza a través de la historia. Madrid: Alianza Editorial, 1996.

DAVIS, Kathy. Reshaping the female body. The dilemma of cosmetic surgery. London: Routledge, 1995.

- Embody-ing theory: beyond modernist and posmodernist readings of the body". In: DAVIS, Kathy. Embodied practices. Feminist perspectives on the body. London: Sage Publications, 1997, pp. 3-15.

- The making of our bodies, ourselves. How feminism travels across borders. Durham; London: Duke University Press, 2007.

ERGAS, Yasmine. El sujeto mujer: el feminismo de los años sesenta-ochenta. In: DuBY, Georges; PERROT, Michelle. Historia de las mujeres. T. 10. El siglo XX. La nueva mujer. Madrid: Taurus, 1993, p. 155-183.

HARAWAY J., Donna. Ciencia, cyborgs y mujeres. La reinvención de la naturaleza. Madrid: Cátedra-Universidad de Valencia, 1995.

LAURETIS, Teresa de. Tecnologías de género. In: RAMos, Carmen (Ed.). El género en perspectiva. De la dominación universal a la representación múltiple. México: Universidad Autónoma Metropolitana-I, 1986, p. 231-278.

Le Breton, David. Antropología del cuerpo y la modernidad. Buenos Aires: Nueva Visión, 2002 [1990].

Adiós al cuerpo. México: La Cifra Editorial, 2007 [1999]. 
LIPOVETSKY, Gilles. El imperio de lo efímero. La moda y su destino en las sociedades modernas. Barcelona: Compactos Anagrama, 2004 [1987].

MARION YOUNG, Iris. Throwing like a girl and other essays in feminist philosophy and social theory. Bloomington; Indianapolis: Indiana University Press, 1990.

Muñiz, Elsa. Cuerpo y corporalidad. Lecturas sobre el cuerpo. In: AgUILAR, Miguel Ángel; REID, Anne (Ed.). Tratado de psicología social. Perspectivas socioculturales. BarceIona: Anthropos-Universidad Autónoma Metropolitana-I, 2007, p. 265-282.

—. Las prácticas corporales. De la instrumentalidad a la complejidad. In: Muñiz, Elsa. Disciplinas y prácticas corporales. Una mirada contemporánea. Barcelona: Anthropos, 2010.

- La cirugía cosmética: ¿Un desafó a la naturaleza? México: CONACyT-UAM, 2011.

SChOPenhaUer, Arthur. El amor, las mujeres, la muerte y otros temas. México: Porrúa, 1991.

Vigarello, Georges. Historia de la belleza. El cuerpo y el arte de embellecer desde el Renacimiento hasta nuestros días. Buenos Aires: Nueva Visión, 2005.

WaJCMAN, Judy. El tecnofeminismo. Madrid: Universitat de Valéncia, 2006.

WEITZ, Rose. The politics of women's bodies. Sexuality, appearance, and behavior. New York: Oxford University Press, 2003.

WITTIG, Monique. El pensamiento heterosexual. Madrid: Egales, 2005.

YEHYA, Naief. El cuerpo transformado. Cyborgs y nuestra descendencia tecnológica en la realidad y en la ciencia ficción. México: Paidós Amateurs, 2001.

Filmes

Las mujeres verdaderas tienen curvas (2002). Directora, Patricia Cardoso, México. Flashdance.

Las mujeres perfectas (2004). Director, Frank Oz, EU. 